\title{
Aproximaciones al exilio de Tomás Segovia a través de la 'fidelidad' de Goethe, Cesare Pavese y Albert Camus
}

\author{
Eugenia HOUVENAGHEL \\ Universiteit Gent
}

\begin{abstract}
RESUMEN
En este estudio, enfocamos el concepto de 'exilio' de Tomás Segovia (Valencia 1927 México 2011). Para ello, recurrimos a la noción de 'fidelidad' ya que Segovia considera el destierro una 'experiencia de fidelidad-infidelidad'. Con el fin de llegar al mejor entendimiento de los orígenes del concepto de 'fidelidad' nos remontamos a sus ensayos de los años 50 y 60 (Sextante 1991) en los que la noción aparece por primera vez. Para Segovia, influenciada, en parte, por el existencialismo francés, la verdadera 'fidelidad' no es estática, sino dinámica: es un proyecto individual, humano para el que no hay recetas, ni valores fijos ni un camino predilecto. La 'fidelidad' de Segovia es, además, una 'fidelidad' creativa, que se renueva sin cesar: es una actitud cambiante que linda, en determinadas circunstancias, con la 'infidelidad'. La interpretación dinámica e innovadora que Segovia propone posibilita la delimitación de un territorio limítrofe en el que 'fidelidad' e 'infidelidad' se tocan un instante. Es en esta zona fronteriza se sitúa la 'condición de exilio' de Segovia.
\end{abstract}

Palabras clave: Tomás Segovia, exilio, fidelidad, literatura europea.

An approximation to the exile of Tomás Segovia through the 'fidelity' of Goethe, Cesare Pavese and Albert Camus

\begin{abstract}
To study the concept of 'exile' used by Tomas Segovia (Valencia 1927 - México 2011), we resort to the notion of 'fidelity', given that the author considers the exile as an 'experience of fidelity-infidelity'. In order to understand the origins of Segovia's concept of 'fidelity', we go back in time to his essays written in the 1950s and 1960s (Sextante 1991), in which this notion appears for the first time. In Segovia's interpretation, clearly influenced by French existentialism, 'fidelidy' is not static but dynamic: it is an individual project, a human plan for which there exist no recepies, no fixed values nor a preferred method. He emphasizes the innovative and creative dimension of 'fidelity', which renews itself constantly: true 'fidelity' is a changing attitude which borders, in certain circumstances, on 'infidelity'. Segovia's dynamic and innovative interpretation makes it possible to mark out a bordering territory in which fidelity and infidelity meet. In this border zone Segovia's 'condition of exile' is situated.
\end{abstract}


Key words: Tomás Segovia, Exile, Loyalty, European literature.

SUMARIO: 1. Una vida marcada por el exilio. 2. El exilio de Tomás Segovia: una experiencia de fidelidad-infidelidad. 3. Aproximaciones a la 'fidelidad' de Goethe, Cesare Pavese y Albert Camus, 3.1. El Goethe fiel y el Goethe infiel, 3.2. La fidelidad infiel de Cesare Pavese y de los neorrealistas italianos, 3.3. El revés de la fidelidad de Albert Camus. 4. La fidelidad a la luz del existencialismo francés. 5. Un exilio entre fidelidad e infidelidad

\section{Una vida marcada por el exilio ${ }^{1}$}

La vida del premiado poeta $^{2}$ y ensayista ${ }^{3}$ hispano-mexicano Tomás Segovia (Valencia 1927-México 2011) está marcada por el destierro. Con nueve años emprendió, al estallar la Guerra Civil el camino del exilio a Francia. Posteriormente, residió algunos años en Casablanca para llegar a México en 1940, a la edad de 12 años. México se convirtió en su país de adopción: Segovia estudió en la UNAM y el Colegio de México, se casó ${ }^{4}$ en México y sus hijos son mexicanos. A partir del año 1957, ingresó como profesor en la UNAM y dirigió la Revista Mexicana de Literatura. En 1985, Tomás Segovia regresó de nuevo a España, instalándose en Madrid pero fue en México donde el poeta murió en el 2011, a los 84 años.

Pocos años antes de su muerte, el poeta se alzó con el Premio de Poesía Federico García Lorca (2008). El jurado del Premio caracterizó al poeta por medio de una referencia a la situación del exilio; Segovia es un autor "de las dos orillas, ya que personaliza a esa generación de poetas que llegó a México por la Guerra Civil, se formó aquí y volvió a España" (El Mundo, 10/10/2008). Sin embargo, cuando lo llamaron "el poeta de las dos orillas del Atlántico", Segovia "respondió que en realidad lo era de todas las orillas, no solo de la mexicana y la española" (Sánchez, en línea). Segovia manifestó su "sorpresa" tras conocer la concesión del Premio, ya

${ }^{1}$ Agradezco mucho la lectura minuciosa que Inmaculada Plaza Agudo realizó del presente estudio y que ha contribuido a mejorar el texto.

${ }^{2}$ Ha publicado una veintena de libros de poesía, y su obra poética ha sido recogida en su mayoría en Poesía 1943-1997 por el FCE. Su primer libro de poesía se titula La luz provisional y es de 1950. Posteriormente escribió Apariciones (1957), Cuaderno del nómada (1978), Cantata a solas (1985) Lapso (1986) y Noticia natural (1992). En su carrera de poeta, obtuvo varios premios literarios, entre los cuales destacan el Xavier Villaurrutia en 1972, el premio Magda Donato en 1974, el premio Octavio Paz en el 2000 y el premio Internacional de Poesía Federico García Lorca en el 2008.

${ }^{3}$ Casi la totalidad de sus artículos y ensayos (publicados en diversos periódicos y números de revistas) se han recogido en 3 volúmenes editados por la Universidad Autónoma Metropolitana (1988-1991).

${ }^{4}$ Primero con Michèle Alban y después con la autora Inés Arredondo. 
que se consideraba "una figura que tiende a ser olvidada", al no pertenecer "a ninguna corriente, país o partido" (El Mundo, 10/10/2008).

En efecto, Segovia prefiere ubicar sus raíces "más que en la tierra, en el viento" (Sánchez, en línea). Aunque el autor algunas veces tematiza el exilio ${ }^{6}$, no le gusta profundizar en la presencia del exilio como tema en su obra. Así, en una encuesta de $1978^{7}$, respondió tajantemente a la pregunta sobre si el exilio influye, en cuanto tono o tema, en la obra de un poeta, apuntando hacia la esterilidad -en el contexto de la investigación literaria- de este tipo de interrogantes $(200) .{ }^{8}$ El autor advirtió que consideraba el exilio no un tema sino 'un sentido que envuelve todos los demás temas' y, para explicar mejor el carácter englobante del exilio, el autor lo comparó con 'otras condiciones generales' de la vida tales como el sexo, la localización histórica o las características físicas de una persona (204). La respuesta evasiva del autor presenta el destierro como una dimensión muy amplia, carente de sentido preciso, y no nos acerca a un mejor entendimiento del concepto de exilio de Segovia. La respuesta recalca, más que nada, que no es en este nivel temático donde toma sentido el destierro para Tomás Segovia.

En este estudio, nos proponemos indagar en un concepto que, según nuestra hipótesis, sí nos ayuda a precisar el significado que el autor concede al exilio: la 'fidelidad'. La 'fidelidad' es una noción recurrente en la obra, tanto poética ${ }^{9} \mathrm{y}$ dramática ${ }^{10}$ como ensayística ${ }^{11}$, de Tomás Segovia, sobre todo en los años 50 y 60 .

${ }^{5}$ Segovia nunca ha pertenecido a ninguna escuela literaria ni a ningún partido.

${ }^{6}$ El reciente volumen Sobre exiliados (2007) reúne artículos de Segovia sobre autores y artistas que viven en el exilio. Se trata de una compilación de artículos y ensayos ya publicados de manera dispersa en otras recopilaciones.

${ }^{7}$ Se reúnen dos textos bajo el título 'Respuestas del exilio': a) una encuesta de un profesor de la Universidad de Estrasburgo de 1978 titulada 'Explicación' (199-210) y b) 'Exiliarse del exilio', un texto basado en un diálogo epistolar de 1986. Los textos se encuentran en la segunda sección de la recopilación de ensayos Sextante, titulado 'Posturas' $(160-236)$.

8 “[...] preguntarme si creo que influye en la poesía es como preguntarme si creo que haber nacido y ser mortal influye en la poesía. Pues sí señor, me temo que sí, pero me resisto a que me hagan creer que he dicho algo cuando contesto esto." (1991: 201).

${ }^{9}$ El poeta ahondó, por ejemplo, en el tema en el poema 'Fidelidad' (Anagnórisis, 1967) y en Suite del infiel (1965). Véase la Obra poética (1943-1997) de Tomás Segovia, recopilada en el 2000 por el FC. También en su obra poética de los años 90, retomó el tema de fidelidad: pensemos en la colección Fiel imagen (1996).

${ }^{10}$ Segovia desarrolló la idea de 'fidelidad' en su única pieza dramática, Zamora bajo los astros (1959). La pieza recuerda Los justos de Albert Camus y se inscribe claramente en la línea filosófica existencialista (Paulino Ayuso 381 y 388). Albert Camus y Tomás Segovia intercambiaron cartas en 1957 sobre el texto dramático; las cartas se publicaron como anejo en la nueva edición de Zamora bajo los astros (2011). 
Es a la misma noción de 'fidelidad' que Segovia recurriría posteriormente en "Respuestas al exilio" (1978) y en "Exiliarse del exilio" (1986) (1991: 199-219), para abordar la cuestión del exilio.

\section{El exilio de Tomás Segovia: una experiencia de fidelidad-infidelidad}

Para Segovia, la vivencia del exilio, se presenta 'en principio [como] una experiencia bastante negativa' (1991: 209). Es lo que Segovia denomina la experiencia del exilio 'accidental' que se reduce a un 'episodio' de la vida de un ser humano (1991: 203). El ensayista denuncia el exilio entendido como mera 'experiencia episódica' (1991: 204) porque -limitado a la mera añoranza por un paísconstituye 'un tema en el que nos encerramos sin poder ni concluir y abandonarlo, ni abrirlo'. Más aún, concebida así, la experiencia del exilio equivale, incluso, a una 'parálisis' o una 'renuncia a vivir' (1991: 209). No es este tratamiento negativo el que da sentido al exilio, subraya Segovia, puesto que 'la añoranza por un país perdido, seguramente legítima, no pasa de ser una nostalgia sentimental si no comprende al mismo tiempo que la pérdida es más nuestra que lo perdido, que la restauración de lo perdido sería una negación de nuestra vida más radical aún que su ausencia, porque es esa vida misma la que la hizo perdido' (1991: 209).

Segovia propone superar el exilio accidental llevando la experiencia del destierro a otro nivel, abriéndola a la dimensión de la vida entera, convirtiéndola en un 'marco' desde el cual se interpretan otras temáticas vitales. A este nivel el ensayista lo llama la 'condición' del exilio (1991: 204). Así se supera la esterilidad del exilio 'episódico' o 'accidental' y se consigue hacer de él un triunfo, porque, según Segovia, este destierro superior y englobante se convierte en una clave de interpretación, en 'nuestra manera de entender (quizás mejor que otros) algunos aspectos de la vida humana personal e histórica' (1991: 209). A modo de ejemplo, Segovia explica que la voz poética de León Felipe ${ }^{12}$ se inscribe en la visión del exilio como una condición que sirve de marco para la exploración de temáticas

\footnotetext{
${ }^{11}$ En la recopilación de ensayos Sextante (Ensayos III, 1991), el autor elaboró en varios artículos -escritos en su mayor parte entre 1955 y 1965- el concepto de 'fidelidad'. En 1954, Segovia hace uso del concepto en el marco de la imagen de Goethe propuesta por dos especialistas del mundo hispánico: Ortega y Gasset y Alfonso Reyes. En varios ensayos redactados entre 1957 y 1962, Tomás Segovia recurre a la noción de 'fidelidad' en el contexto histórico de la posguerra europea, al explorar la vida y obra de autores franceses e italianos relevantes de la época, tales como Albert Camus y Cesare Pavese.

${ }^{12}$ León Felipe se exilió, después de haber participado en la guerra civil como militante republicano hasta 1938, definitivamente a México. Se convirtió en agregado cultural de la embajada de la República española en el exilio, produjo una obra poética que se suele relacionar con la obra de Walt Whitman y en la cual la libertad ocupa un lugar destacado. En 1967 murió en la Ciudad de México.
} 
humanas. (1991: 204 y 205). Superar la experiencia negativa del exilio significa, para Segovia, disociar el exilio de la pérdida de la lengua materna y de la pérdida de los usos literarios que se hacen de la lengua materna en la patria. Segovia insiste en la imperiosa necesidad de abandonar una idea del exilio según la que los que residen en la patria tienen un derecho exclusivo sobre el uso poético de la lengua española. Ni la patria ni la lengua española pertenecen a cierta comunidad, en la visión de Segovia, y cuando uno acepta esta visión libre y abierta de país e idioma, consigue superar el nivel 'accidental' del exilio y llegar al nivel en el que el exilio toma sentido.

Y es aquí cuando entra el concepto de 'fidelidad' en el discurso de Segovia: para llevar el exilio accidental a un nivel desde el que toma sentido, conviene adoptar una actitud que es doble frente a la lengua española y la patria: una actitud a la vez infiel y fiel y que se sitúa en el mismo lugar de entrecruzamiento de fidelidad e infidelidad. Así, los poetas que han vivido de manera abierta el exilio transformándolo en una 'condición' viven 'una experiencia de la fidelidad-infidelidad, de una infidelidad que es una fidelidad (o viceversa)' (1991: 208) y son considerados a la vez como 'excluidos de la fidelidad y guardianes de la fidelidad' (1991: 208). Es sobre todo la actitud frente a la lengua la que causa dicha situación doble. Como explica Segovia: 'la fidelidad de un grupo concreto a su lengua concreta aparece fundada en un inevitable oscurecimiento de su naturaleza y olvido de sus orígenes, y esa luz es así para ella una violación y una infidelidad.' (1991: 209)

Con el fin de concretar la situación fronteriza y ambigua de fidelidad infiel a la lengua, el ensayista recurre al ejemplo que ofrece la poesía de Rubén Darío. La recepción en España de la poesía de Rubén Darío ilustra cómo su actitud creativa frente a la lengua se percibe como infiel: 'cuando Rubén Darío [...] trajo una canción que implicaba una visión más radical, en tantos aspectos, de la naturaleza de la lengua española', España 'aceptó la canción pero consideró la visión como una violación y una infidelidad' de la lengua (1991: 209). Segovia subraya que dicho uso creativo del idioma es, de hecho, una fidelidad a la lengua española. 'Negarse a admitir eso', subraya Segovia, 'es adoptar la actitud del casticismo que, como es sabido, no nace de la realidad de la lengua aunque sea una actitud lingüística, sino más bien de la aplicación violenta a la lengua de unas actitudes que ignoran su realidad [...]' (1991: 208).

A partir de estas declaraciones de Tomás Segovia de 1978 y 1986 sobre su entendimiento del exilio como una 'experiencia de fidelidad-infidelidad', lanzamos la hipótesis según la cual la noción de 'fidelidad' nos acerca a una comprensión más profunda del exilio de Tomás Segovia. Para analizar su concepto de 'fidelidad', nos remontamos a sus primeros escritos ensayísticos de los años 50 y 60 , en los cuales aparece el concepto por primera vez en su obra. ¿Qué significados toma la noción de 'fidelidad' en aquellos ensayos? ¿Cómo nos pueden ayudar estos sentidos para entender mejor el 'exilio' de Tomás Segovia? Son las preguntas que guían nuestra lectura. 


\section{Aproximaciones a la 'fidelidad' de Goethe, Cesare Pavese y Albert Camus} El Goethe fiel y el Goethe infiel

La noción de fidelidad aparece por primera vez en el artículo "Goethe, don Alfonso y los jóvenes" (1954) ${ }^{13}$, en el que Segovia se aproxima al breve esbozo biográfico ${ }^{14}$ que Alfonso Reyes, goethista mexicano de renombre, dedica al autor alemán en México con ocasión de la recepción del premio del Instituto Mexicano del Libro. Su discurso se relaciona, como explica Segovia, con la imagen goethiana creada por Ortega y Gasset, veinte años antes en el ensayo "Pidiendo un Goethe desde dentro" (1932) ${ }^{15}$. Ortega y Gasset propone la imagen de un Goethe 'infiel' mientras que la visión alternativa de Alfonso Reyes presenta un Goethe fiel. Segovia enfatiza que la controversia atañe a todos los estudiosos de la obra goethiana (140): 'Todo el que habla de Goethe tiene en boca esta palabra: destino. Los unos para mostrar en Goethe el más acabado ejemplo de fidelidad al destino; los otros, para presentar un Goethe ejemplarmente infiel a su destino.' Segovia, a su vez, aprovecha la polémica para precisar su concepto de fidelidad y, a partir de esta definición refinada de la noción, matizar tanto la fidelidad como la infidelidad del poeta alemán.

Segovia inicia su discurso aclarando la idea del Goethe infiel que propone Ortega y Gasset. El filósofo español plantea en 1932 que, si bien es cierto que la obra del Goethe de la primera fase parece anunciar una auténtica revolución literaria romántica, la producción del Goethe posterior no realiza la promesa del primer período. Ortega se refiere a la evolución notable del trabajo de Goethe, quien reniega el Romanticismo de la primera fase para identificarse, posteriormente, con el equilibrio grecolatino del clasicismo. El poeta alemán no ha llevado a cabo su proyecto inicial, destaca Ortega y Gasset, por lo tanto, no ha sido fiel a su naturaleza íntima, a su destino 'desde dentro' que coincide con el momento histórico del romanticismo. Frente a la interpretación de Ortega, Segovia avisa que no hay que confundir el destino y el período histórico que le toca vivir a un autor. 'Desde el momento en que esta fidelidad tiene lugar en la historia', explica Segovia, 'es fácil hacernos creer, mediante una hábil transposición de términos, que hay que ser fiel a la historia, y no en la historia.' (1991: 141). Si se equipara el destino al tiempo histórico, Goethe traiciona su destino, puesto que termina por 'ser infiel al

${ }^{13}$ Ensayo (139-142) que se incluye en la sección "Minimalia" de la primera serie '1.Pensar al día' del volumen Sextante.

${ }^{14}$ Trayectoria de Goethe (1954).

15 Segovia destaca que, para ofrecer esta alternativa, Reyes no se dirige en 1954 directamente contra la imagen goethiana de Ortega y Gasset, sino que simplemente propone una imagen distinta. El texto de Ortega y Gasset de 1932 se publicó con motivo de los 100 años de la muerte del poeta alemán. 
romanticismo, que era el hecho histórico de su momento.${ }^{16}$ Pero, considerada la traición del romanticismo desde otro punto de vista, se convierte en otra fidelidad, la fidelidad al proyecto poético del autor que precisamente no coincide con su tiempo histórico: 'Esta otra fidelidad no podía exigirle, naturalmente, que actuara fuera del romanticismo; pero sí que, actuando en el romanticismo, actuara contra él.' (1991: 142) La infidelidad de Goethe al período histórico del romanticismo se transforma, en la lectura de Segovia, en una fidelidad a otro principio superior, su destino en la acepción de su proyecto poético de revolucionar la literatura.

A continuación, Tomás Segovia presenta la imagen alternativa de Goethe sugerida por Alfonso Reyes. Si Ortega señala que Goethe ha traicionado su destino, Alfonso Reyes se opone a esta visión, mostrando, a través de los datos biográficos que se incluyen en su Trayectoria de Goethe (1954), que el poeta alemán es 'el más acabado ejemplo de fidelidad al destino'. La intensa asimilación de la Grecia clásica en Weimar le ha ayudado a formar y dar sustancia a la conciencia alemana de aquella época y a equilibrar su propia mente. Segovia no profundiza tanto en la interpretación que Reyes hace de los hechos de la vida goethiana, sino que reanuda más bien con el proceso comunicativo en torno al nuevo libro de Alfonso Reyes sobre Goethe en 1954. Hace hincapié en el público de jóvenes al que Alfonso Reyes se dirige con esta ocasión, presentando su discurso como un alegato orientado hacia el futuro, cuyo objetivo consiste en influenciar a la juventud. Alfonso Reyes propone, fundamentalmente, 'una idea del destino' frente a un grupo de jóvenes que todavía 'no han vivido su destino'. Cuando Reyes se dirige a la juventud, su propósito es, en la lectura de Segovia, el de cambiar la idea que esta generación tiene de la vida y obra de Goethe, transformando, incluso, la idea que tienen aquellos jóvenes de la poesía y de la literatura. Así interpreta Segovia la posición de profunda 'fidelidad' de Goethe que Alfonso Reyes defiende: como un estímulo dirigido hacia la nueva generación para cambiar su aproximación a la literatura.

El pacto de 'fidelidad' se realiza, en el caso de Goethe, no con una persona ni con un valor abstracto tal como la amistad o el amor sino con una misión poética, un proyecto literario. ¿Cuáles son los rasgos principales que Segovia atribuye a esta alianza con la literatura? Resalta una primera característica: al ensayista le gusta apuntar hacia la frontera borrosa que separa la fidelidad de la traición. Una sola actitud -en el caso de Goethe la identificación con el clasicismo grecolatino en el período en Weimar- se explica simultáneamente como una fidelidad y una

${ }^{16}$ La lectura de Ortega y Gasset se entiende dentro del marco de la filosofía orteguiana, el circunstancialismo, que ha dejado una fuerte impronta en el pensamiento latinoamericano. El eje central de su filosofía lo constituye la relación entre la vida humana y la historia. Partiendo de esta visión historicista del hombre, Ortega plantea que el hombre interactúa estrechamente con las circunstancias que le rodean. 
infidelidad. Lo que parece ser una infidelidad al momento histórico del romanticismo, resulta ser una fidelidad a otro valor de mayor relevancia: el proyecto poético del autor alemán. Deducimos también que el concepto que Segovia se construye de la fidelidad es un concepto creativo en el que ocupa un lugar fundamental la idea de innovación. La imagen que la juventud tiene de la literatura en el México de los años 50 necesita ser transformada y para ello sirve, al modo de ver de Segovia, la presentación que propone Reyes de un Goethe fiel. El escritor mexicano recurre a dicha imagen de Goethe para mostrar a los jóvenes que la fidelidad a la literatura coincide precisamente con una actitud dinámica que exige la constante promesa de innovación.

\section{La fidelidad infiel de Cesare Pavese y de los neorrealistas italianos}

La fidelidad parece combinarse con la idea de la vida en cuatro ensayos (de entre 1955 y 1962) dedicados al caso de Pavese, cuyo diario El oficio de vivir (publicación póstuma, 1952) es el testimonio de un suicida. Sin embargo, destaca Segovia, el testimonio que se transmite a través del diario no es un mensaje a favor de la muerte, sino a favor de la vida, o lo que es lo mismo, a la fidelidad (1991: 48). En el caso de Pavese, la vida es la muerte, la vida es un tormentoso amor de la muerte: 'su evidente nostalgia de la muerte', destaca Segovia, 'adquiere también un sentido vital' (1991: 47). La muerte es para Pavese como 'la vida por debajo', 'lo que la vida les promete y depara', 'el centro de su vida', 'siendo lo único a lo que vale la pena ser fiel' (1991: 47). Para Pavese, la auténtica fidelidad está ligada a la muerte; su nostalgia de la muerte 'viene a ser una extraña fidelidad' (1991: 47). 'Vivió por la fidelidad, que en su caso se llamaba muerte' (1991: 48), concluye Segovia. El acto del suicidio se vincula, en el discurso de Segovia, no solo con la vida y con la fidelidad, sino también con el amor. Tanto es así, que el suicidio, que viene 'cuando su antiguo amor vuelve a llamarle', se describe como un acto de amor: 'Entonces ya no hay posibilidad de ser infiel: el amante torturado y difícil deja de luchar y se duerme entre sus brazos' (1991: 48). El discurso de Segovia vincula la fidelidad de Pavese, a través de la muerte, con la vida auténtica y la pasión amorosa. 'Toda la historia de su vida parece la historia de un tormentoso amor, y este amor es el de la muerte. Pero precisamente un amor tan tormentoso, con tanta historia secreta, tan fiel y, en una palabra, tan vivo, da la trama de una compacta y positiva existencia' (1991: 47).

En cuatro ensayos dedicados a los neorrealistas italianos, de 1955 y 1956, Segovia vuelve a tender un puente entre el concepto de fidelidad y la vida, que cobra otro sentido en el contexto de la creación artística. En "Fidelidad de Italia" 
(1955), el ensayista va contrastando el contexto difícil ${ }^{17}$ en el que trabajan estos escritores con la alta calidad de su trabajo. Subraya la actitud discrepante de la generación neorrealista frente a la moral predominante de la Italia fascista de aquel entonces. Al preguntarse cómo puede surgir una serie de novelistas de tanta calidad en un momento histórico tan contraproducente, parece sugerir que es precisamente la oposición a la moral vigente la que es el motor creador de las novelas tan logradas. El régimen fascista se considera como la razón misma del nacimiento de una generación tan talentosa. Es, precisamente, 'cuando los demás se sienten extraviados y alejados de sus núcleos vitales' cuando este pueblo 'encuentra lozana en su fondo una semilla viva y perenne que ofrecer' (1991: 90). Es, precisamente, 'en esta misma Italia, otra vez invadida, dominada y despedazada como en tiempos de Felipe II' (1991: 92), donde surge una literatura llena de esperanza. Es 'entre la ceniza y las ruinas' que aparece la fuerza fresca y llena de vida de esta generación de narradores. Dicha adhesión a una moral distinta es, para Segovia, una forma de sobrevivir a los contratiempos: los novelistas neorrealistas italianos, siendo fieles a sus propios valores, 'se han salvado de los desastres de nuestro tiempo' (1991: 92).

La pregunta siguiente que orienta la reflexión ensayística de Segovia es cómo explicar la capacidad de la generación italiana de sacar una literatura ejemplar bajo la dominancia de un régimen totalitario. Segovia recurre a los clichés que existen sobre el pueblo italiano: considera que su carácter poco racionalista, asistemático, meridional explica su resistencia a los totalitarismos del siglo XX, a los cuales considera 'la última y feroz consecuencia de un racionalismo rígido, autoritario y abstracto' (1991: 92). Segovia opone en este contexto el caso italiano al caso alemán: 'Mussolini, contrariamente a Hitler, no gobernaba sobre un pueblo sistemático, $[\ldots]$ lógico, sino sobre un pueblo más fiel a la vida que a las ideologías, a lo concreto que a lo abstracto, a las situaciones que a los pronósticos.' (1991: 92) La generación italiana, de acuerdo con estos principios, hace más que sobrevivir a los contratiempos, también 'muestra' (1991: 92) algo, ofrece una lección moral. Segovia insiste en particular en la superioridad moral de quienes se niegan a aceptar

${ }^{17}$ La generación de neorrealistas italianos se caracteriza por su actitud antifascista, que a unos los llevó al exilio y a otros a la cárcel en los años '30 y '40. Cesare Pavese (19081950), en primer lugar, en los años 1935-6, fue condenado, por su participación en actividades antifascistas, a un año de confinamiento o exilio en el sur de la península. Carlo Levi (1902-1975), igual que Pavese, fue exiliado a un pueblo remoto de Italia en los años 1935-1936. Corrado Alvaro (1895-1956), a su vez, fue obligado a dejar Italia durante los años '30 por sus contribuciones en el periódico antifascista Il Mondo. Elio Vittorini (19081966) no fue exiliado pero sí sufrió las consecuencias de la censura y fue capturado y metido en prisión en 1942 por sus actitudes contra el régimen de Mussolini. ${ }^{17}$ Alberto Moravia (1907-1990) es un caso complejo que sufrió sobre todo las consecuencias relacionadas con la censura del régimen fascista. 
los valores del régimen fascista, destacando que la actitud de los neorrealistas italianos es 'más profunda' (1991: 89), 'honda y segura' en comparación con la solución de aceptar la moraleja predominante, en comparación con 'el deber de ser infieles a la vida en nombre del Nuevo Orden o de cualquier otro orden impositivo' (1991: 92). 'Ningún sistema abstracto', sostiene Segovia, 'aunque esté respaldado por la más poderosa policía, puede pretender absorber toda nuestra capacidad de fidelidad' (1991: 92).

Efectivamente, el discurso de Segovia en "Fidelidad de Italia" es explícitamente ético: el ensayista considera una obligación moral esta fidelidad a valores que están en peligro: 'Si Camus ${ }^{18}$ nos ha enseñado que debemos ser fieles a ciertas cosas que hoy nos aparecen terriblemente amenazadas', estos novelistas que surgen ofrecen 'una lección' o 'un ejemplo' $(89,90,92)$ de una moralidad superior. ¿Qué es lo que muestra precisamente esta generación? La generación nos enseña que 'por debajo de las leyes están los hombres vivos, por debajo de la historia la naturaleza viva, por debajo de los racionalismos la realidad viva.' (1991: 92) La lección ofrecida por los neorrealistas se deja resumir en tres palabras: 'fidelidad, renacimiento, esperanza' (1991: 91). Estos términos son, para Segovia, 'como tres incisiones hacia un mismo centro, un centro para el que no encuentro una definición mejor que la vida, lo vivo' (1991: 91).

\section{El revés de la fidelidad de Albert Camus}

En dos ensayos de 1957 dedicados a la obra de Camus ${ }^{19}$, aparece el concepto de fidelidad para interpretar un relato del autor francés titulado "La mujer adúltera"20. La fidelidad aparece en el contexto de la vida de pareja pero no se trata de un adulterio ordinario. ¿En qué consiste este adulterio fuera de lo común? La mujer protagonista del relato -Janine- se encuentra en un matrimonio que se está convirtiendo en una cárcel: su vida está llena de restricciones. Cuando está de viaje con su marido en el norte de África, una noche abandona el lecho conyugal para subir a una torre y contemplar a solas el desierto y los astros hasta que amanezca. La experiencia de la libertad es tan sensual que se la puede considerar como adúltera. Pero dicho adulterio misterioso al marido sería, en la lectura de Segovia, al mismo tiempo una 'fidelidad más rara, más difícil, más desnuda' (1991: 23) a sí

${ }^{18}$ La fidelidad se vincula también con la vida en 'Camus y la universalidad' (1957, 2734). El contexto ahora es el de la creación artística: Segovia subraya que es por su fidelidad a la vida que Camus ha conseguido dar al arte en la época de los '50 una gran dignidad.

19 "Nuevas obras de Albert Camus" (18-24) y "El reino de Camus" (24-27) en la sección 'Pensar al día'.

${ }^{20}$ El cuento forma parte de la recopilación El exilio y el reino de 1957 (L'exil et le royaume). 
misma. Una infidelidad fiel, pues. Se trata de un adulterio que corresponde a un deseo tan auténtico de vivir que, más que una infidelidad a un matrimonio carente de pasión, es, en la lectura de Segovia, una fidelidad a la pasión auténtica de vivir.

El concepto de fidelidad aparece de nuevo cuando Segovia lee (en "Camus ida y vuelta", 1959) la recopilación de crónicas sobre Argelia Actuelles III (1958), escritas por Camus entre 1939 y 1958. En opinión de Segovia, la postura de Camus de 1939 sobre la situación en Argelia no ha cambiado en 1958. Albert Camus (1913-1960) se mudó de Argelia a Francia en 1940 en una especie de auto-exilio después de haber tomado posición contra la opresión colonial en su país de nacimiento. Durante la guerra de independencia de Argelia, Camus estaba a favor de una autonomía mayor de Argelia, pero no apoyaba una independencia completa; creía que los Pieds-Noirs y los árabes podían convivir. Segovia destaca la diferencia entre la situación en 1939 y la en 1958 y considera la actitud de Camus en ambos momentos como 'el revés y el derecho ${ }^{21}$ de la fidelidad' (1991: 35). Refiriéndose a la época de 1958, Segovia pone en duda 'no sólo que la postura de Camus sea la más adecuada, sino incluso que sea la más fiel a su propio pensamiento' (1991: 36) al destacar que 'mientras que hace veinte años aquello era una actitud revolucionaria y casi subversiva, que le valió incluso una especie de exilio, hoy resulta un programa que coincide demasiado con el de De Gaulle' (1991: 36). La actitud 'fiel' a la conciencia o lo moralmente bueno de aquel entonces se ha convertido, pues, en la época en la que Segovia redacta este ensayo, en una postura 'infiel'.

Segovia explica la postura 'infiel' del autor francés en 1958 refiriéndose al dilema moral de Camus, cuya fidelidad hacia los colonos franceses entra en conflicto con su fidelidad hacia los argelinos cuando la guerra de la independencia de Argelia se inicia en 1954. Camus, nacido en Argelia, se solidariza con el millón de Pieds-Noirs que viven en Argelia porque es uno de ellos. En caso de la independencia de Argelia, los colonos tendrían que dejar Argelia, y tendrían que regresar a Francia. Sin embargo, Segovia insiste en que, considerando la situación objetivamente, el eventual regreso de los colonos franceses a Francia sería una 'repatriación'. Destaca, para ello, que los colonos no son argelinos, sino franceses, y lo hace desaprobando la actitud de los colonos franceses hacia los árabes: 1) no se produjo ninguna fusión con los argelinos durante cien años y 2) los colonos siempre han recibido mejores salarios que los árabes. Es predominante la actitud reacia al colonialismo en el discurso de Segovia: 'Vivir en un país gozando de los privilegios

\footnotetext{
${ }^{21}$ Aludiendo a la recopilación de ensayos El revés y el derecho.
} 
que otro país concede, y que niega a los aborígenes, no es pertenecer a ese país, es poseerlo.' $(1991: 37)^{22}$

\section{La fidelidad a la luz del existencialismo francés}

En los ensayos dedicados a la fidelidad de Goethe, Cesare Pavese y Albert Camus, los contextos en los cuales aparece la fidelidad varían: el concepto se vincula con las decisiones éticas que toman autores italianos, franceses y alemanes en situaciones muy diferentes, que van desde la relación de pareja, pasando por la creación artística y la política a la oposición entre la vida y la muerte. Si bien es cierto que los ámbitos en los que Segovia recurre al concepto son muy variados, tienen en común la idea de un cambio frente a una mentira o una existencia que no es auténtica como punto de partida. Un matrimonio que ya no funciona bien, un gobierno que propone un sistema autoritario, una vida que ya no parece digna de ser vivida y un pueblo que ve su país liderado por otro pueblo. En todas estas situaciones, el ensayista sugiere, en nombre de la fidelidad, que hace falta introducir un cambio para superar la situación negativa, resolviéndola mediante la toma de una determinada decisión libre.

Otra dimensión común en los usos que Segovia hace de la fidelidad es la predilección por la zona fronteriza entre fidelidad e infidelidad. Segovia trata situaciones controvertidas y rebatibles, en las cuales no es patente ni unívoca la respuesta a la pregunta sobre si una determinada actitud es fiel o infiel. Al ensayista le sirve no tanto la idea de fidelidad ni la de infidelidad, sino la línea divisoria entre fidelidad e infidelidad, que se convierte, en el discurso de Segovia, en una frontera movediza. En los casos que Segovia refiere, las apariencias engañan: lo que parece ser una infidelidad a un determinado sistema o institución de hecho equivale a una actitud fiel a otro valor que se presenta como superior, más profundo, más auténtico. Así es como la fidelidad a un principio se equipara a la rebeldía contra otro sistema, instituto o valor. La mujer adúltera de Camus, en esta noche misteriosa y sensual, más que ser infiel a su matrimonio vacío, es fiel a la pasión auténtica de vivir. Cesare Pavese, al tomar la decisión de suicidarse, más que ser infiel a la vida, es fiel a la muerte, que en su caso corresponde al centro mismo de la vida. Los neorrealistas italianos optan por la fidelidad a la vida en detrimento de la fidelidad al sistema fascista. La postura de Camus en defensa de los Pieds-Noirs, si bien es cierto que era una actitud fiel en el año '39, posteriormente se ha convertido en una postura infiel frente a la población legítima de Argelia.

A nuestro modo de ver, el marco del existencialismo francés reúne y da coherencia a los rasgos del uso de la fidelidad en los ensayos de Segovia. El

${ }^{22}$ Segovia subraya el paralelismo con la situación de colonización en Hispanoamérica (37) para explicar su capacidad de entender la situación de Argelia. 
existencialismo francés es en efecto una doctrina de la acción y del progreso, que va en contra del quietismo y del estancamiento. Para relacionar a Segovia con el existencialismo, nos apoyamos en el fuerte vínculo intelectual que une a Segovia a la Francia de la postguerra. En efecto, aunque México se convierte en el país en el que reside la mayor parte de su vida, el contacto que mantiene con países europeos y con la vida cultural europea -sobre todo con la Francia de los años 50 y 60 pero también con España- es estrecho. ${ }^{23}$ La fidelidad es una noción relevante en la Europa de la época mencionada: tras las experiencias traumáticas que vivió la humanidad durante la Primera Guerra Mundial y la Segunda Guerra Mundial, los pensadores franceses del existencialismo se hicieron preguntas en torno al sentido de la existencia humana. Reaccionando contra el racionalismo, Albert Camus y Jean-Paul Sartre propusieron temas filosóficos más cercanos a la vida individual, tales como la libertad, la muerte, las posibilidades de la existencia, la responsabilidad. Uno de los temas que cobraron mayor importancia en la busca de una ética existencial era precisamente la fidelidad del individuo: fidelidad con el yo mismo, con los otros, con la situación histórica.

Para Sartre (El existencialismo es un humanismo, 1945), el ser humano no se considera un proyecto divino sino un proyecto puramente existencial. En su visión, es la constante preocupación por la realización de ese proyecto la que mueve a las personas. Sin embargo, este proyecto no se ha esbozado de antemano, ni existe una tabla de valores en la que puede apoyarse el ser humano, sino que traza su proyecto de existencia en plena libertad en el momento de tomar decisiones y de privilegiar ciertos valores sobre otros. El hombre se hace hombre en la medida en la que realiza, de manera activa, su proyecto individual. La actitud auténtica es la de 'buena fe', el comportamiento de un ser humano que asume la responsabilidad completa de su ser en una determinada situación y que decide actuar para modificar o denunciar su situación en función de la realización de su proyecto. La 'mala fe' correspondería a la falta de acción, al refugio en el quietismo de un ser humano que se escapa de sus responsabilidades. Es el ser humano quien decide libremente y que dispone de la posibilidad de realizarse a sí mismo; porque la vida humana solo adquiere sentido en la medida en la que el ser humano da significado a su existencia.

${ }^{23} \mathrm{Su}$ trabajo como traductor y en diversas editoriales en París es un lazo importante que le une a Europa igual que la buena acogida de su obra poética en España. El vínculo con la cultura europea se confirma cuando, tras jubilarse en 1984, Segovia alterna su residencia entre Madrid y el sur de Francia. Acorde con esta afinidad con Europa, es la cultura europea la que muchas veces le ocupa al ensayista Segovia. 
${ }^{24}$ El existencialismo subraya la trascendencia de las decisiones libres del individuo: el hombre existe persiguiendo fines transcendentales que van más allá de su propia circunstancia y subjetividad.

Segovia, en sus ensayos, parece inscribirse en la línea de pensamiento sartreano, refiriéndose a la fidelidad como un proyecto individual, humano, para el que no hay recetas, ni valores fijos ni un camino predilecto. La fidelidad de Segovia es una fidelidad creativa, que se renueva sin cesar. Segovia ubica las decisiones privadas, artísticas y políticas que acaba de comentar en el mismo cruce entre fidelidad e infidelidad, en el lugar -tan característico del clima de posguerra- entre la esperanza de una situación mejor y el aceptar una situación deplorable. En suma, la fidelidad que maneja Segovia en estos ensayos tiene mucho en común con la actitud auténtica de la 'buena fe' sartreana, pero reinventa la responsabilidad del hombre con la vida como una responsabilidad, no frente a la política, sino frente al quehacer literario, a un proyecto poético.

\section{Un exilio entre fidelidad e infidelidad}

Antes de concluir, es fundamental recordar el carácter limitado en el tiempo del presente estudio. Hemos centrado nuestro análisis en una serie de ensayos de los años 50 y 60, es decir, ensayos que el propio Segovia describe, ya en $1990^{25}$, como 'textos ligados a una actualidad que ya no lo es' (1991: 8). Por un lado, es verdad que la insistencia en esta zona fronteriza entre fidelidad e infidelidad se entiende mejor cuando la inscribimos en la dinámica que caracteriza la posguerra, y que se mueve entre 'la esperanza de un orden social más justo', y la realidad de la confrontación con los regímenes autoritarios de la época. Segovia compara el mundo de posguerra con una medalla de dos caras (1991: 192): por un lado, existe este sueño que el ensayista califica de 'grandioso' (1991: 195) y, por otro, la guerra fría que frustra estas esperanzas de cambiar el mundo. ${ }^{26}$ Por otro lado, a nuestro modo de ver no es cierto - como sugiere el propio autor- que el 'interés de estos textos sea hoy ya puramente histórico' (1991: 8). La relevancia del concepto de 'fidelidad' a la vez se entiende dentro del marco histórico y sobrepasa los límites

${ }^{24}$ A su modo de ver, el hombre no solo es responsable de sí mismo, sino que, al elegir los valores de su proyecto, construye una imagen del hombre tal y como debe ser; por lo tanto, el hombre es responsable de la humanidad entera.

${ }^{25}$ Fecha del prólogo (“Advertencia, 1991, 7-9) de la recopilación de ensayos Sextante (Ensayos III) publicada en 1991.

${ }^{26}$ En el año 1980, cuando coinciden la muerte de Tito (nacido en 1892) y la muerte de Sartre (nacido en 1905), Segovia concluye que el fallecimiento de ambas figuras en el mismo año significa que una época ha tocado definitivamente su fin ("Fábula de fuentes" 189-198). 
temporales de dicha época: nos permite localizar el origen de un concepto al que Segovia recurre para explicar su visión del exilio.

¿Por qué el concepto de fidelidad manejado por Segovia es tan idóneo para aplicarse al exilio? Tal aptitud se explica a partir de uno de los rasgos preponderantes que Segovia atribuye a la fidelidad: el dinamismo. El ensayista no propone una visión limitada de la fidelidad, sino que desarrolla la noción de manera matizada, sugiriendo una acepción bivalente del término, en la que la fidelidad a la lengua, al proyecto poético y a la patria no es el polo opuesto de la infidelidad ni se aleja necesariamente mucho de la traición. La interpretación dinámica que Segovia propone posibilita la delimitación de un territorio limítrofe en el que fidelidad e infidelidad se tocan. La zona en la que lindan fidelidad e infidelidad nos ofrece la clave para entender el concepto de exilio que propone Segovia.

Conviene situar la noción de 'fidelidad' no solo en el eje espacial sino también en el eje temporal para llegar a una comprensión de la misma. Cuando pasamos revista a las diferentes dimensiones temporales inherentes al concepto de exilio, el ensayista no subraya tanto el pacto de fidelidad establecido en el pasado con la tierra natal, su lengua y su literatura, sino que privilegia una visión en la que los cambios del presente y la conciencia de una constante evolución futura son el motor de la acción auténticamente fiel. Se trata del instante en el que las circunstancias cambiadas de la actualidad o la esencia dinámica del objeto mismo con el que se ha establecido el pacto exigen la toma de una decisión aparentemente infiel a la alianza inicial. Así, la 'fidelidad' se convierte en un concepto esencialmente innovador que, en su sentido auténtico, invita a la rebeldía contra criterios inmóviles. La reinterpretación continua le permite al exiliado mantenerse verdaderamente fiel a los pactos realizados y a los compromisos aceptados. Los exiliados de hoy en día que desean permanecer fieles necesitan hacer un trabajo de recontextualización y relectura crítica para aceptar desafíos relacionados con las problemáticas actuales y venideras. Así, una tradición literaria, una lengua o una vida en el exilio que permanecen estáticas se traicionan: $\sin (\mathrm{r})$ evolución no hay fidelidad.

\section{BIBLIOGRAFÍA}

ORTEGA Y GASSET, José.

2005 Pidiendo un Goethe desde dentro en Obras completas. Tomo IV. Madrid: Revista de Occidente.

REYES, Alfonso.

1994 Trayectoria de Goethe en Obras completas. Tomo XXVI. México: FCE.

COHEN-Solal, Annie.

1985 Sartre 1905-1980. Paris: Gallimard. 
CONTAT, Michel y Michel RYBALKA.

2001 Les écrits de Sartre. Paris: Gallimard.

PASCUAL GAY, Juan.

2003 "Ceremonia del moroso: El poema evoca y convoca", Texto Crítico, Jan-June 6 (12), pp. 85-93.

PAULINO AYUSO, José.

2011 "Tomás Segovia: Zamora bajo los astros", en El exilio republicano de 1939 y la segunda generación. Manuel Aznar Soler y José Ramón López García. Sevilla: Renacimiento, pp. 380-392.

SÁNCHEZ, Nelly.

"Tomás Segovia, el poeta de las dos orillas", en línea en [http://www.noroeste.com.mx/publicaciones.php?id=475026],

SARTRE, Jean-Paul. [consultado el 14 de marzo del 2013].

2000 El existencialismo es un humanismo. Barcelona: Ed. Edhasa .

2005 El ser y la nada. Buenos Aires: Losada.

2006 El existencialismo es un humanismo. México: UNAM.

SEGOVIA, Tomás.

1991 Sextante. Ensayos III. México: UAM.

2000 Obra poética 1943-1997. México: FCE.

2005 Zamora bajo los astros. México: Ediciones sin nombre.

2007 Sobre exiliados. México: El Colegio de México.

2011 Zamora bajo los astros. Editorial Florián de Ocampo.

UNAMUNO, Miguel de.

2005 En torno al casticismo. Madrid: Cátedra.

WEINBERG, Liliana.

2008 "La poesía reconoce de forma oficial a Tomás Segovia" en Informador.com.mx, Guadalajara

2012 "El ensayo y la buena fe". El ensayo hispánico: cruces de géneros, sintesis de formas. Eds. Castilleja Diana, Eugenia Houvenaghel y Dagmar Vandebosch.Droz: Genève, pp. 21-46. http://www.informador.com.mx/entretenimiento/2008/45017/6/lapoesia-espanola-reconoce-de-forma-oficial-a-tomas-segovia.htm [consultado el 17 de diciembre del 2012] 